\title{
PEDIATRICS
}

\section{The Oxford-Durham Study: A Randomized, Controlled Trial of Dietary Supplementation With Fatty Acids in Children With Developmental Coordination Disorder}

Alexandra J. Richardson and Paul Montgomery

Pediatrics 2005;115;1360-1366

DOI: $10.1542 /$ peds.2004-2164

This information is current as of May 3, 2005

The online version of this article, along with updated information and services, is located on the World Wide Web at:

http://www.pediatrics.org/cgi/content/full/115/5/1360

PEDIATRICS is the official journal of the American Academy of Pediatrics. A monthly publication, it has been published continuously since 1948. PEDIATRICS is owned, published, and trademarked by the American Academy of Pediatrics, 141 Northwest Point Boulevard, Elk Grove Village, Illinois, 60007. Copyright @ 2005 by the American Academy of Pediatrics. All rights reserved. Print ISSN: 0031-4005. Online ISSN: 1098-4275.

\section{American Academy of Pediatrics}

DEDICATED TO THE HEALTH OF ALL CHILDREN ${ }^{\mathrm{m}}$ 


\title{
The Oxford-Durham Study: A Randomized, Controlled Trial of Dietary Supplementation With Fatty Acids in Children With Developmental Coordination Disorder
}

\author{
Alexandra J. Richardson, DPhil(Oxon)*, and Paul Montgomery, DPhil(Oxon) $\ddagger \S$
}

\begin{abstract}
Background. Developmental coordination disorder (DCD) affects $\sim 5 \%$ of school-aged children. In addition to the core deficits in motor function, this condition is associated commonly with difficulties in learning, behavior, and psychosocial adjustment that persist into adulthood. Mounting evidence suggests that a relative lack of certain polyunsaturated fatty acids may contribute to related neurodevelopmental and psychiatric disorders such as dyslexia and attention-deficit/hyperactivity disorder. Given the current lack of effective, evidence-based treatment options for DCD, the use of fatty acid supplements merits investigation.

Methods. A randomized, controlled trial of dietary supplementation with $\omega-3$ and $\omega-6$ fatty acids, compared with placebo, was conducted with 117 children with DCD (5-12 years of age). Treatment for 3 months in parallel groups was followed by a 1-way crossover from placebo to active treatment for an additional 3 months.

Results. No effect of treatment on motor skills was apparent, but significant improvements for active treatment versus placebo were found in reading, spelling, and behavior over 3 months of treatment in parallel groups. After the crossover, similar changes were seen in the placebo-active group, whereas children continuing with active treatment maintained or improved their progress.

Conclusions. Fatty acid supplementation may offer a safe efficacious treatment option for educational and behavioral problems among children with DCD. Additional work is needed to investigate whether our inability to detect any improvement in motor skills reflects the measures used and to assess the durability of treatment effects on behavior and academic progress. Pediatrics 2005;115:1360-1366; developmental coordination disorder, fish oil, supplementation, RCT, reading, spelling, behavior, omega-3 fatty acids, dyspraxia.
\end{abstract}

ABBREVIATIONS. ADHD, attention-deficit/hyperactivity disorder; DCD, developmental coordination disorder; DSM-IV, Diagnostic and Statistical Manual of Mental Disorders, Fourth Edition; CTRS-L, Conners' Teacher Rating Scales, Long Version.

From the *University Laboratory of Physiology, Oxford, United Kingdom; and Departments of ‡Psychiatry and §Social Policy and Social Work, University of Oxford, United Kingdom.

Accepted for publication Jan 13, 2005.

doi:10.1542/peds.2004-2164

Conflict of interest: Dr Richardson works as a consultant to companies that make fatty acid supplements.

Address correspondence to Alexandra J. Richardson, DPhil(Oxon), University Laboratory of Physiology, Parks Road, Oxford OX1 3PT, United Kingdom. E-mail: alex.richardson@physiol.ox.ac.uk

PEDIATRICS (ISSN 0031 4005). Copyright ( 92005 by the American Academy of Pediatrics.
$\mathrm{O}$ mega-3 fatty acids are essential for normal brain development and function and must be provided by the diet. However, their low levels in modern diets in developed countries are a known risk factor for physical disorders such as cardiovascular and inflammatory diseases. ${ }^{1}$ Converging evidence indicates that fatty acid deficiencies or imbalances may also contribute to a range of adult psychiatric and neurologic disorders ${ }^{2}$ and to several common and overlapping childhood neurodevelopmental disorders, including attention-deficit/hyperactivity disorder (ADHD), dyslexia (specific reading difficulties), dyspraxia (developmental coordination disorder [DCD]), and autistic spectrum disorders. ${ }^{3}$

Although this suggests that dietary supplementation with $\omega-3$ fatty acids may be of benefit in these conditions, results from the few small, randomized, controlled trials published to date have been mixed. ${ }^{4}$ Some benefits from $\omega-3 / \omega-6$ supplementation were reported for children with dyslexia or $\mathrm{ADHD}, 5,6$ whereas 2 studies found no benefits for ADHD with the $\omega-3$ fatty acid docosahexaenoic acid alone. ${ }^{7,8}$ No randomized, controlled trials of fatty acid treatment for either autism or DCD/dyspraxia have yet been reported, although one small open study suggested possible benefits for dyspraxic children. ${ }^{9}$

DCD, as defined in the Diagnostic and Statistical Manual of Mental Disorders, Fourth Edition (DSM-IV), involves specific impairments of motor function independent of general ability. ${ }^{10}$ It affects $\sim 5 \%$ of children to a serious degree and shows substantial overlap with ADHD, dyslexia, and autistic spectrum disorders. ${ }^{11,12}$ In the school environment, the primary obstacles to academic achievement that children with DCD face involve difficulties with written language (ie, the overlap with dyslexia) and/or difficulties with organizational skills, attention, and behavior (ie, the overlap with ADHD symptoms), although these are typically compounded by low selfesteem and social problems. Children who met criteria for both DCD and ADHD at 7 years of age showed a particularly poor prognosis when evaluated at age 22, in terms of both academic achievement and psychosocial adjustment. ${ }^{13}$

From a brain-behavior perspective, the disturbances of perception, attention, and behavior found in DCD/dyspraxia show parallels with the effects of fatty acid deficiency, as documented in animal studies. ${ }^{14,15}$ Given the current lack of treatment options for such children, fatty acid supplements would offer 
an acceptable safe intervention if found to be effective. We therefore assessed the effects of dietary supplementation with $\omega-3$ and $\omega-6$ fatty acids among children with DCD, between 5 and 12 years of age, who were identified from a geographically defined, general school population. The primary outcome measures were standardized, age-adjusted measures of motor skills, literacy skills (word reading and spelling), and teacher-rated behavioral and learning difficulties usually associated with ADHD. The hypothesis was that treatment for 3 months with a fatty acid supplement would lead to significant improvements, compared with placebo, in these key areas of functioning.

\section{METHODS}

\section{Study Design}

This was a randomized, double-blind, placebo-controlled trial involving treatment in parallel groups for 3 months, followed by a 1-way crossover (placebo to active treatment) for an additional 3 months. Active treatment was a food supplement containing $\omega-3$ and $\omega-6$ fatty acids, whereas the placebo was a similar supplement containing olive oil. All primary outcome measures were obtained at pretreatment baseline and 3- and 6-month follow-up points.

Comparison of the effects of parallel treatments for 3 months was the primary focus of the study. This treatment period is the minimum suitable for this kind of intervention, because of the slow turnover of these fatty acids in neuronal membranes. ${ }^{16} \mathrm{~A}$ full crossover design would be inappropriate, for similar reasons.

\section{Participants}

\section{Eligibility Criteria}

The study was approved by the local research ethics committee and was open to mainstream schoolchildren, 5 to 12 years of age, who met DSM-IV criteria for DCD but were not receiving any treatment for this condition. DCD diagnoses were confirmed with age-standardized measures (full-scale IQ ${ }^{17}$ of $>70$ and motor skills below the 15th percentile with objective testing ${ }^{18}$ ) and case histories from teachers and parents, which verified that the children's impairments interfered with academic achievement and activities of daily living. Other eligibility criteria included provision of baseline data for any of the key outcome measures, permission from the primary caregiver, who provided written informed consent, and confirmation that the child was not under medical supervision for any major physical or mental health condition (eg, epilepsy, diabetes mellitus, depression, or chronic fatigue syndrome), as confirmed by the child's physician.

\section{Recruitment}

Participants were drawn from the first 12 schools in County Durham, United Kingdom, that were willing to assist with the study. Potential volunteers were identified by teachers at those schools, from all children whom they suspected of having DCDtype difficulties, and all data were collected from those school sites. The recruitment process yielded 117 eligible participants, who were randomized as shown in Fig 1.

\section{Interventions}

The active treatment was a supplement containing $80 \%$ fish oil and $20 \%$ evening primrose oil (a ratio similar to that used in previous studies $)^{5,6}$ in gelatin capsules. The daily dose of 6 capsules provided $\omega-3$ fatty acids (558 mg of eicosapentaenoic acid and $174 \mathrm{mg}$ of docosahexaenoic acid) and the $\omega-6$ fatty acid $\gamma$-linoleic acid $(60 \mathrm{mg}$ ) plus $9.6 \mathrm{mg}$ of vitamin $\mathrm{E}$ (natural form, $\alpha$-tocopherol). Placebo treatment consisted of olive oil capsules, which were carefully matched with the active treatment with respect to both appearance and flavor.

On weekdays, treatments were administered at the schools, by coordinating teachers, in 3 divided doses of 2 capsules each (early morning, lunchtime, and late afternoon). For weekend use, children were given capsules to take at home on a similar schedule, under parental supervision. At the end of each 3-month treatment period, compliance was assessed through counts of capsules remaining, cross-checked against the daily logbooks kept by teachers who administered and supervised the ingestion of supplements on weekdays and who also checked for any adverse events. A percentage figure for treatment compliance was calculated from a combination of teacher logbooks and counts of capsules returned from supplies provided to parents for use during weekends and holidays.

\section{Randomization and Allocation}

A computer-generated random sequence was used to prepare the treatments in sequentially numbered containers. Two registers, one revealing only the treatment group (coded A or B) and the other noting the actual identity of the treatments (active or placebo), were kept in a remote secure location by an independent third party until all study data had been collected, collated, checked, and verified. Treatments were assigned to each participating school in sequentially numbered blocks matching the number of children taking part. The allocation sequence was concealed completely from all staff members involved in data collection or analysis. Participants, those administering the interventions, and those assessing the outcomes were all blinded with respect to group assignments.

\section{Outcomes}

The primary outcome measures were the changes observed during 3 months of treatment, in parallel groups, on age-standardized tests of (1) motor function (assessed with the Movement Assessment Battery for Children ${ }^{18}$ ), (2) reading and spelling achievement (assessed with the Wechsler Objective Reading Dimensions ${ }^{19}$ ), and (3) teacher-rated ADHD-related symptoms (assessed with Conners' Teacher Rating Scales, Long Version [CTRS$\mathrm{L}]^{20}$ ).

\section{Analyses}

All data were analyzed by the authors.

\section{Power Calculations}

Because this was the first study of its kind, power calculations were based on the nearest comparable study, 5 involving children with specific reading difficulties assessed with the parent-rated version of the Conners' ADHD rating scales used here. Scores on the DSM-IV total ADHD scale showed a treatment effect of 0.6 SD. Power calculations indicated that group sizes of 42 would give $>80 \%$ power at the .05 level. A target sample size of 50 subjects per group was therefore chosen for this study.

\section{Planned Comparisons}

Planned group comparisons were performed on the primary outcome measures. Data distributions were not normal; therefore, nonparametric tests (Mann-Whitney, 2-tailed tests) were used for all analyses. Missing data (see flowchart in Fig 1) were imputed by using the last observation carried forward.

\section{Multiple Comparisons}

In the case of our behavioral change measures, it was recognized that, in comparisons of the 2 treatment groups with respect to changes in all 13 of the age-standardized CTRS-L scales, some group differences could reach conventional significance levels simply by chance. However, statistical correction for multiple comparisons would be inappropriate, because scores on many of these scales are intercorrelated (because they are derived from different but overlapping combinations of the 59 items in the inventory). Group comparisons were therefore performed by using the total raw scores obtained by summing across all items. To allow comparisons with other studies, however, results from the age-standardized scales were also computed.

\section{Role of the Funding Source}

The study was cofunded by the Dyslexia Research Trust and the Durham Local Education Authority, neither of which had any involvement in study design, analysis and interpretation of data; writing of the report; or the decision to submit the article for publication. 

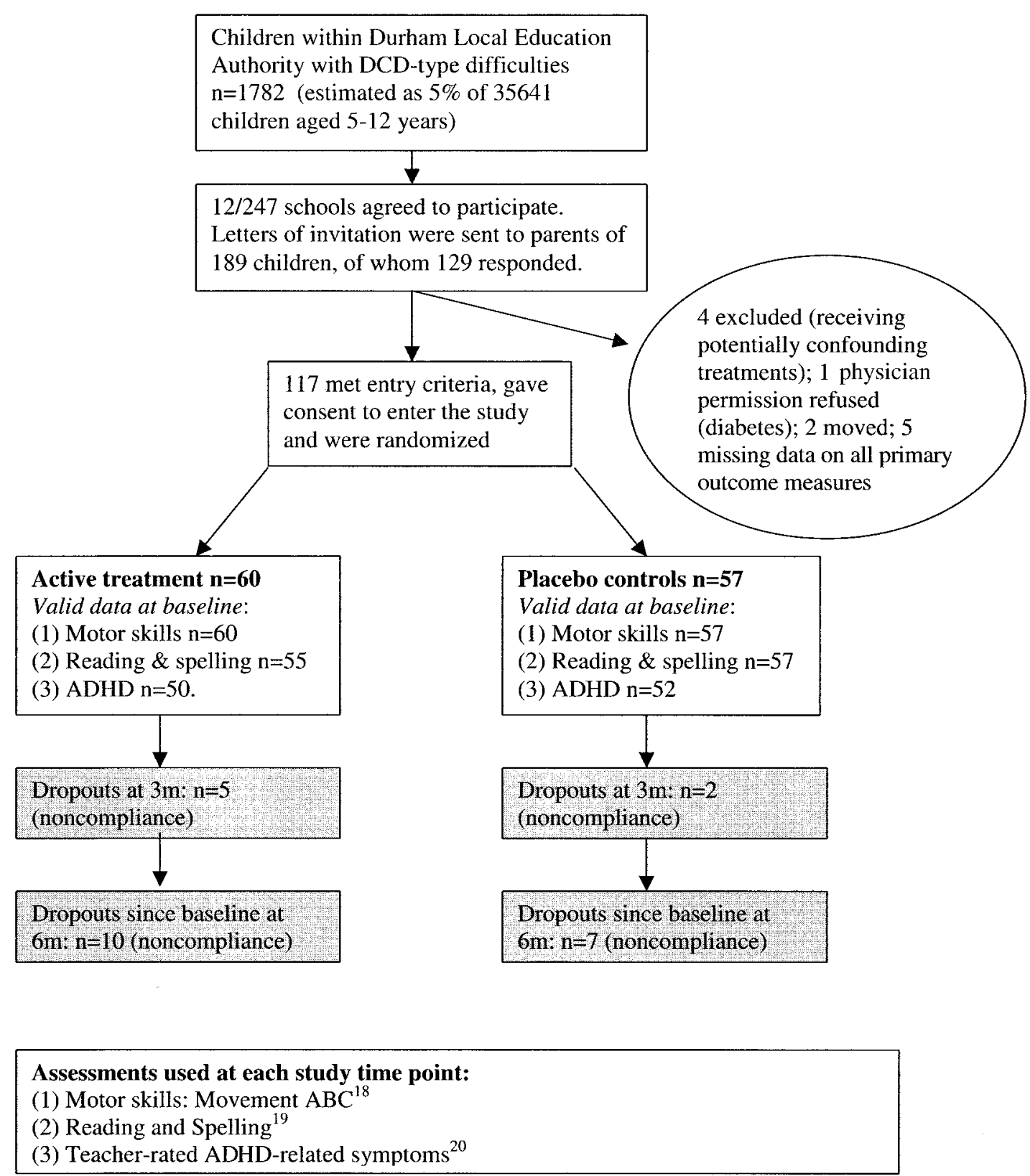

Fig 1. Flow of participants through the study. Although these data show the numbers of participants at each stage of the trial, all analyses were performed on an intention-to-treat basis, with the last observation carried forward, for all randomized children provided that baseline data for that measure were available. Therefore, the numbers of participants $(n)$ reported in our analyses (see Tables 1-3) differ slightly among the 3 main outcome measures (motor skills analyses, $n=117$; reading and spelling, $n=112$; ADHD-related symptoms, $n=102)$. ABC indicates Assessment Battery for Children; GP, general.

\section{RESULTS}

\section{Study Sample}

The flow of participants through the study is shown in Fig 1. The sample consisted of 78 boys and 39 girls, with a mean age of 105.8 months (SD: 16.3 months; range: 70-147 months). The mean Wechsler Intelligence Scale for Children full-scale IQ was 90.3 (SD: 8.1; range: $71-110$ ), ie, $\sim 0.67$ SD below the general population average. The verbal IQ mean was 94.0 (SD: 7.8; range: 76-116) and the nonverbal IQ mean was 88.4 (SD: 8.3; range: 71-110). Attrition rates were low, and attrition was entirely attributable to refusal to take part in additional assessments. Seven children dropped out before the 3-month point (5 in the active treatment group and 2 in the placebo group), and a total of 17 children dropped out by 6 months (10 in the active treatment group and 7 in the placebo group). In all such cases, the children first stopped taking the capsules; therefore, data on the capsule intake of these children were not included in the figures for treatment compliance during each study phase, as given below.

\section{Parallel-Group, 3-Month Treatment Phase Compliance Rates}

The mean treatment compliance rate at 3 months for all children who completed this phase of the study $(n=110)$ was $88.7 \%$ (SD: $7.1 \%)$, and rates did 
not differ between the treatment groups. No adverse effects were reported.

\section{Motor Skills}

Age-standardized scores from the Movement Assessment Battery for Children are shown in Table 1. At baseline, mean percentile scores were below the 6 th percentile. The scores improved to the 12th percentile during the 3-month parallel-group treatment phase, but the mean changes did not differ between the 2 treatment groups.

\section{Reading and Spelling}

Reading and spelling ages are shown in Table 2. Before treatment, mean achievement scores for these measures were $\sim 1$ year below chronologic age. During the 3-month, parallel-group phase, the mean increases in reading age were 9.5 months (SD: 13.9 months) for active treatment and 3.3 months (SD: 6.7 months) for placebo, a highly significant difference $(z$ $=2.87, P<.004)$. The mean increases in spelling age were 6.6 months (SD: 11.4 months) for active treatment and 1.2 months (SD: 5.0 months) for placebo; again, the group difference was highly significant $(z$ $=3.36, P<.001)$.

\section{ADHD-Related Symptoms}

Age-standardized scores on the CTRS-L, assessing ADHD-related symptoms, are shown in Table 3. At baseline, mean scores for both groups were on average slightly more than $1 \mathrm{SD}$ above population means. To the best of our knowledge, no child had a formal ADHD diagnosis. However, 32 of the 102 children with CTRS-L scores at baseline (17 boys and 15 girls), ie, $31 \%$ of this sample, had scores $\geq 2$ SD above the general population average on the DSM-IV total scale of the CTRS-L. Very similar proportions were within the same range for the DSM-IV hyperactivity and DSM-IV inattention scales. Scores at this level would place these children within the usual clinical range for a DSM-IV ADHD diagnosis, although this could be confirmed only with a full psychiatric assessment, which was not feasible in this study.

After 3 months of treatment in parallel groups, reductions on all CTRS-L global scales were significantly greater for active treatment than for placebo. Results for the subscales were similar, with only perfectionism and social problems scales failing to show a significant advantage for active treatment.

As noted earlier, correction for multiple comparisons would be inappropriate, because scores on many of these age-standardized scales involve some of the same items and are thus intercorrelated. To avoid this potential confounding, CTRS-L total raw scores were also examined.

For active treatment, scores decreased from a mean of 74.7 (SD: 26.7) to 58.1 (SD: 27.7), a reduction of $>0.5 \mathrm{SD}$ during the 0 - to 3-month parallel-group treatment phase. In contrast, almost no change was seen in the placebo group (pretreatment mean: 69.5; SD: 33.1; posttreatment mean: 67.9; SD: 34.8). This group difference was highly significant $(z=5.48, P<$ $.0001)$.

At 3 months after treatment, only 24 children (23.5\%) still had CTRS-L scores that placed them in the clinical range for ADHD. Among those receiving active treatment, 7 of the initial 16 no longer fell into this category; in the placebo group, only 1 of 16 improved in this way.

\section{Follow-Up Phase, Months 3 to 6 (1-Way Treatment Crossover)}

The mean treatment compliance rate during the 3to 6-month follow-up phase with 1-way treatment crossover was $85.5 \%$ (SD: $8.6 \%$ ) for all children who completed this phase of the study $(n=100)$, and rates did not differ between groups. The mean increase in motor skills during this period did not differ between groups, as shown in Table 1. With respect to reading and spelling, however, children

TABLE 1. Movement Assessment Battery for Children (Motor Skills) for Active Treatment and Placebo-Crossover Groups at Pretreatment Baseline, 3 Months, and 6 Months

\begin{tabular}{|c|c|c|c|c|c|c|c|c|}
\hline & \multicolumn{4}{|c|}{ Mean Score (SD) } & \multicolumn{2}{|c|}{$\begin{array}{l}\text { 0- to 3-mo Group } \\
\text { Comparisons, } \\
\text { Mann-Whitney } \\
\text { 2-Tailed Test }\end{array}$} & \multicolumn{2}{|c|}{ Mean Score (SD), 6 mo } \\
\hline & \multicolumn{2}{|c|}{ Baseline } & \multicolumn{2}{|c|}{$3 \mathrm{mo}$} & \multirow[t]{2}{*}{ Z } & \multirow[t]{2}{*}{$P$} & \multirow{2}{*}{$\begin{array}{l}\text { Active } \\
\text { LOCF } \\
(n=10)\end{array}$} & \multirow{2}{*}{$\begin{array}{l}\text { Crossover } \\
\text { LOCF } \\
(n=7)\end{array}$} \\
\hline & $\begin{array}{c}\text { Active } \\
(n=60)\end{array}$ & $\begin{array}{l}\text { Placebo } \\
(n=57)\end{array}$ & $\begin{array}{l}\text { Active } \\
\text { LOCF } \\
(n=5)\end{array}$ & $\begin{array}{l}\text { Placebo } \\
\text { LOCF } \\
(n=2)\end{array}$ & & & & \\
\hline Manual dexterity & $10.0(2.5)$ & $9.6(1.9)$ & $8.7(2.8)$ & $8.7(1.9)$ & 0.96 & .4 & $7.4(2.3)$ & $7.6(2.1)$ \\
\hline Ball skills & $2.1(2.5)$ & $2.5(2.8)$ & $1.7(2.3)$ & $1.6(2.2)$ & 0.57 & 6 & $1.1(1.8)$ & $1.1(1.8)$ \\
\hline Static and dynamic balance & $3.5(3.6)$ & $3.1(2.7)$ & $2.5(3.3)$ & $1.8(2.5)$ & 1.03 & .3 & $1.9(2.8)$ & $1.3(2.2)$ \\
\hline Total impairment & $15.6(5.7)$ & $15.2(5.0)$ & $13.1(5.9)$ & $12.1(5.1)$ & 0.42 & .7 & $10.4(4.9)$ & $10.0(5.0)$ \\
\hline Percentile & $5.9(4.6)$ & $5.8(4.3)$ & $12.3(11.2)$ & $12.9(10.1)$ & 0.58 & .6 & $19.5(14.7)$ & $20.0(12.6)$ \\
\hline
\end{tabular}

The scores shown are derived from 8 different subtests of the Movement Assessment Battery for Children, ${ }^{18}$ which are grouped into 3 categories, manual dexterity ( 3 subtests), ball skills (2 subtests), and static and dynamic balance ( 3 subtests). Each subtest yields a crudely age-standardized impairment score, ranging from 0 (no impairment) to 5 (severe impairment). For the manual dexterity and static and dynamic balance categories, the maximal possible impairment score is 15; for ball skills, the maximal possible impairment score is 10 . The total impairment score represents the sum of these 3 categories (maximum of 40). For any of these impairment scores, reductions correspond to improved performance. Percentile scores (relative to general population normative values) are derived from the total impairment scores, with higher percentiles representing better overall motor performance. Because analyses were conducted on an intent-to-treat basis, the total number of participants $(n)$ remained constant throughout the duration of the study, but data for children who had dropped out at each time point were imputed as the last observation carried forward (LOCF), and their numbers are shown. 
TABLE 2. Reading and Spelling Ages for Active Treatment and Placebo-Crossover Groups at Pretreatment Baseline, 3 Months, and 6 Months

\begin{tabular}{|c|c|c|c|c|c|c|c|c|}
\hline & \multicolumn{4}{|c|}{ Mean Age (SD) } & \multicolumn{2}{|c|}{$\begin{array}{l}\text { 0- to 3-mo Group } \\
\text { Comparisons, } \\
\text { Mann-Whitney } \\
\text { 2-Tailed Test }\end{array}$} & \multicolumn{2}{|c|}{ Mean Age (SD), 6 mo } \\
\hline & \multicolumn{2}{|c|}{ Baseline } & \multicolumn{2}{|c|}{$3 \mathrm{mo}$} & \multirow[t]{2}{*}{ Z } & \multirow[t]{2}{*}{$P$} & \multirow{2}{*}{$\begin{array}{l}\text { Active } \\
\text { LOCF } \\
(n=4)\end{array}$} & \multirow{2}{*}{$\begin{array}{c}\text { Crossover } \\
\text { LOCF } \\
(n=7)\end{array}$} \\
\hline & $\begin{array}{l}\text { Active } \\
(n=55)\end{array}$ & $\begin{array}{l}\text { Placebo } \\
(n=57)\end{array}$ & $\begin{array}{l}\text { Active } \\
\text { LOCF } \\
(n=0)\end{array}$ & $\begin{array}{l}\text { Placebo } \\
\text { LOCF } \\
(n=2)\end{array}$ & & & & \\
\hline Reading age & $93.6(18.6)$ & $99.8(25.5)$ & $103.2(28.4)$ & $103.2(27.1)$ & 2.87 & $<.004$ & $114.0(34.1)$ & $116.0(34.1)$ \\
\hline Spelling age & $92.2(16.3)$ & 95.5 (17.6) & $98.8(22.0)$ & 96.7 (17.9) & 3.36 & $<.001$ & $104.1(25.0)$ & $102.8(22.2)$ \\
\hline
\end{tabular}

Reading and spelling ages indicate the level of achievement that would be expected by a normal child of a given chronologic age. These scores were derived from single-word reading and spelling tests from the Wechsler Objective Reading Dimensions ${ }^{19}$ battery. Because analyses were conducted on an intent-to-treat basis, the total number of participants $(n)$ remained constant throughout the duration of the study, but data for children who had dropped out at each time point were imputed as the last observation carried forward (LOCF), and their numbers are shown.

TABLE 3. Scores on the CTRS-L for Active Treatment and Placebo-Crossover Groups at Pretreatment Baseline, 3 Months, and 6 Months (Age Standardized With Respect to General Population Normative Values, in the Form of $t$ Scores: Mean: 50; SD: 10)

\begin{tabular}{|c|c|c|c|c|c|c|c|c|}
\hline & \multicolumn{4}{|c|}{ Mean Score (SD) } & \multicolumn{2}{|c|}{$\begin{array}{l}\text { 0- to 3-mo Group } \\
\text { Comparisons, } \\
\text { Mann-Whitney } \\
\text { 2-Tailed Test }\end{array}$} & \multicolumn{2}{|c|}{ Mean Score (SD), $6 \mathrm{mo}$} \\
\hline & \multicolumn{2}{|c|}{ Baseline } & \multicolumn{2}{|c|}{$3 \mathrm{mo}$} & \multirow[t]{2}{*}{$Z$} & \multirow[t]{2}{*}{$P$} & \multirow{2}{*}{$\begin{array}{l}\text { Active } \\
\text { LOCF } \\
(n=2)\end{array}$} & \multirow{2}{*}{$\begin{array}{l}\text { Crossover } \\
\text { LOCF } \\
(n=3)\end{array}$} \\
\hline & $\begin{array}{c}\text { Active } \\
(n=50)\end{array}$ & $\begin{array}{l}\text { Placebo } \\
(n=52)\end{array}$ & $\begin{array}{l}\text { Active } \\
\text { LOCF } \\
(n=6)\end{array}$ & $\begin{array}{c}\text { Placebo } \\
\text { LOCF } \\
(n=7)\end{array}$ & & & & \\
\hline \multicolumn{9}{|l|}{ Subscales } \\
\hline Opposition & $59.5(13.0)$ & $59.2(13.6)$ & $56.2(12.2)$ & $59.7(13.8)$ & 2.42 & $<.02$ & $54.9(13.1)$ & $56.6(13.5)$ \\
\hline Cognitive problems & $65.9(9.2)$ & $63.9(9.8)$ & $61.2(10.0)$ & $63.0(10.3)$ & 4.13 & $<.0001$ & $59.4(10.4)$ & $60.4(10.1)$ \\
\hline Hyperactivity & $61.9(12.7)$ & $61.0(13.5)$ & $57.3(11.8)$ & $61.3(12.6)$ & 5.08 & $<.00001$ & $55.5(11.0)$ & $58.2(13.3)$ \\
\hline Anxious/shy & $62.8(12.1)$ & $61.3(13.9)$ & $59.3(10.3)$ & $61.3(13.1)$ & 3.03 & $<.002$ & $56.5(10.8)$ & $56.9(12.8)$ \\
\hline Perfectionism & $53.6(9.8)$ & $51.8(9.0)$ & $52.4(9.1)$ & $52.0(9.8)$ & 1.37 & .2 & $52.4(9.8)$ & $50.3(9.6)$ \\
\hline Social problems & $56.8(12.9)$ & $58.1(11.9)$ & $54.9(11.2)$ & $57.8(11.4)$ & 1.72 & $<.09$ & $53.9(11.1)$ & $55.6(10.9)$ \\
\hline \multicolumn{9}{|l|}{ Global scales } \\
\hline Conners' index & $66.2(10.7)$ & $64.0(12.0)$ & $59.9(10.6)$ & $63.8(12.1)$ & 5.78 & $<.00001$ & $58.3(11.6)$ & $61.1(13.5)$ \\
\hline Conners' global restless-impulsive & $66.3(10.7)$ & $64.2(12.2)$ & $60.4(11.0)$ & $64.3(11.9)$ & 5.56 & $<.00001$ & $58.0(11.9)$ & $61.5(13.9)$ \\
\hline Conners' global emotional lability & $61.7(15.2)$ & $59.1(12.2)$ & $58.5(14.1)$ & $59.9(13.1)$ & 2.34 & $<.02$ & $55.4(13.7)$ & $54.8(11.4)$ \\
\hline Conners' global index & $66.9(12.2)$ & $64.1(12.5)$ & $60.8(11.9)$ & $64.4(12.9)$ & 5.62 & $<.00001$ & $58.1(12.8)$ & $60.7(13.8)$ \\
\hline DSM-IV inattention & $65.2(9.9)$ & $64.3(9.8)$ & $60.1(10.2)$ & $62.7(10.1)$ & 3.92 & $<.0001$ & $57.9(11.1)$ & 59.5 (11.3) \\
\hline DSM-IV hyperactivity & $61.1(13.0)$ & $60.4(13.9)$ & $57.1(12.6)$ & $60.2(13.9)$ & 4.87 & $<.00001$ & $55.7(12.3)$ & $58.0(13.8)$ \\
\hline DSM-IV Total ADHD & $64.6(10.9)$ & $63.7(11.5)$ & $59.5(10.8)$ & $62.7(11.9)$ & 5.00 & $<.00001$ & $57.5(11.6)$ & $59.6(12.7)$ \\
\hline
\end{tabular}

The CTRS-L $\mathrm{L}^{20}$ consists of 59 items describing different aspects of child behavior, each endorsed with a 4-point scale. Item scores are combined in different ways to yield raw scores for the 6 subscales and 7 global scales shown, each of which then yields an agestandardized score for comparability with general population normative values. Because analyses were conducted on an intent-to-treat basis, the total number of participants $(n)$ remained constant throughout the duration of the study, but data for children who had dropped out at each time point were imputed as the last observation carried forward (LOCF), and their numbers are shown.

crossing over from placebo to active treatment showed improvements similar to those shown earlier by children receiving active treatment (Table 2). Their mean reading age improved by 13.5 months (SD: 11.9 months), and their spelling age improved by 6.2 months (SD: 6.8 months). Children continuing on active treatment also showed improvements above chronologic age (mean reading age gain: 10.9 months; SD: 11.8 months; mean spelling age gain: 5.3 months; SD: 6.9 months).

In terms of behavior, the placebo-active treatment crossover group showed reductions in CTRS-L scale scores similar to those of the active group in the 0- to 3 -month period (Table 3). Their mean total raw score decreased to 57.8 (SD: 38.0), whereas children continuing with active treatment showed some addi- tional improvement, with their mean total raw score decreasing to 52.6 (SD: 32.8).

\section{DISCUSSION}

To our knowledge, this is the first randomized, controlled trial of this kind among children with DCD. Our hypothesis was that treatment for 3 months with a fatty acid supplement would lead to significant improvements over placebo, as assessed with changes in motor skills, reading and spelling ages, and teacher ratings of behavioral and learning difficulties usually associated with ADHD.

Results showed no effect of treatment on motor skills but significant improvements in reading, spelling, and behavior for active treatment versus placebo during 3 months of treatment in parallel groups. 
After a 1-way treatment crossover (placebo to active), similar changes were seen in the placebo crossover group, whereas children continuing with active treatment maintained or improved their progress.

This study involved 117 children, between 5 and 12 years of age, from mainstream schools in 1 United Kingdom county, all of whom met DCD criteria but were otherwise normal and not receiving any other treatment for their specific learning difficulties. Although it seems unlikely that these children would differ significantly from general population samples in other developed countries, generalizability to other age groups and cultures cannot be assumed. The low rate of dropout and high rate of compliance with treatment indicated that the researchers and teaching staff members provided very strong motivation, which might not be the case in other circumstances. No adverse events were reported, and the high compliance rate also suggests good acceptability of fatty acid supplements.

The improvements in literacy skills and behavior found here are consistent with other reports of benefits from fatty acid supplementation among children selected for dyslexia or ADHD,, 6 but it is noteworthy that no group effect of treatment on motor skills was apparent. The similarity in the effect sizes for ADHD-related symptoms between this DCD sample and one selected with standard criteria for dyslexia $^{5}$ suggests that these results may be more widely generalizable. Although the focus of this investigation was $\mathrm{DCD}$, the high level of comorbidity typically found between these conditions and the heterogeneity within each of them suggest that a symptom-based approach may be more fruitful than an exclusive focus on current diagnostic categories.

In this kind of population, delays in literacy development usually increase over time, indicating the value of early intervention. Children in the placebo group fell even more behind with spelling during the 0 - to 3-month parallel-group phase, although they did show average progress in reading. In contrast, children receiving active treatment made 3 times the expected normal gain in reading age and twice the normal gain in spelling age, bringing their average scores toward normative values. In the follow-up phase, they continued to make improvements above what would be expected for chronologic age.

With global measures of teacher-rated behavior, children receiving active treatment improved by $\sim 0.5 \mathrm{SD}$ in the 0 - to 3-month parallel-group phase, with some additional improvements in the follow-up phase. In the placebo group, no changes were observed until the children crossed over to active treatment. The first-line treatment for ADHD symptoms in most developed countries is methylphenidate, for which a recent meta-analysis ${ }^{21}$ found an overall effect size of 0.78 with the Conners' index but little or no evidence of durability beyond 4 weeks of treatment. By comparison, in this study the effect sizes with this measure were 0.55 for the first 3 months and 0.70 over 6 months for children receiving fatty acid treatment throughout.
The problems faced by this kind of population are enduring. Follow-up studies indicate that, without specific intervention, children with DCD and ADHD at 7 years of age have unusually poor academic, social, and health outcomes in adolescence and young adulthood. ${ }^{13,22,23}$ Studies with older populations are therefore required, in addition to replication of the current findings. Although our data suggest that continuing treatment from 3 to 6 months may produce additional benefits, issues of both durability and maintenance of treatment effects also require attention in future studies.

The optimal dosage and combination of fatty acids are at present unknown. An $\omega-3 / \omega-6$ ratio of 4:1 was selected for this study on the basis of previous work indicating benefits in dyslexia and ADHD, 5,6 although in this case the marine oil contained a higher eicosapentaenoic acid/docosahexaenoic acid ratio. Additional studies are needed to establish both the optimal composition of fatty acid treatments and dose-response relationships.

This study was a pragmatic one designed to investigate the efficacy of fatty acid treatment and can therefore shed no light on the possible mechanisms at work. The findings do suggest, however, that fatty acid supplements of this type may be a safe, tolerable, effective treatment for improving academic progress and behavior among children with DCD.

\section{ACKNOWLEDGMENTS}

Thanks are due to the many staff of Durham Local Education Authority, who assisted with recruitment and data collection for this study. Particular thanks are also due to all the pupils and parents involved for their participation.

\section{REFERENCES}

1. Simopoulos AP. The importance of the ratio of $\omega-6 / \omega-3$ essential fatty acids. Biomed Pharmacother. 2002;56:365-379

2. Haag M. Essential fatty acids and the brain. Can J Psychiatry. 2003;48: 195-203

3. Richardson AJ, Ross MA. Fatty acid metabolism in neurodevelopmental disorder: a new perspective on associations between attention-deficit/ hyperactivity disorder, dyslexia, dyspraxia and the autistic spectrum. Prostaglandins Leukot Essent Fatty Acids. 2000;63:1-9

4. Richardson AJ. Clinical trials of fatty acid treatment in ADHD, dyslexia, dyspraxia and the autistic spectrum. Prostaglandins Leukot Essent Fatty Acids. 2004;70:383-390

5. Richardson AJ, Puri BK. A randomized double-blind, placebocontrolled study of the effects of supplementation with highly unsaturated fatty acids on ADHD-related symptoms in children with specific learning difficulties. Prog Neuropsychopharmacol Biol Psychiatry. 2002;26: 233-239

6. Stevens L, Zhang W, Peck L, et al. EFA supplementation in children with inattention, hyperactivity, and other disruptive behaviours. Lipids. 2003;38:1007-1021

7. Voigt RG, Llorente AM, Jensen CL, Fraley JK, Berretta MC, Heird WC. A randomized, double-blind, placebo-controlled trial of docosahexaenoic acid supplementation in children with attention-deficit/hyperactivity disorder. J Pediatr. 2001;139:189-196

8. Hirayama S, Hamazaki T, Terasawa K. Effect of docosahexaenoic acidcontaining food administration on symptoms of attention-deficit/ hyperactivity disorder: a placebo-controlled double-blind study. Eur J Clin Nutr. 2004;58:467-473

9. Stordy BJ. Dark adaptation, motor skills, docosahexaenoic acid, and dyslexia. Am J Clin Nutr. 2000;71:323S-326S 
10. American Psychiatric Association. Diagnostic and Statistical Manual of Mental Disorders, Fourth Edition, Text Revision. Washington, DC: American Psychiatric Association; 2000

11. Kadesjo B, Gillberg C. Developmental coordination disorder in Swedish 7-year-old children. J Am Acad Child Adolesc Psychiatry. 1999;38:820-828

12. Dewey D, Kaplan BJ, Crawford SG, Wilson BN. Developmental coordination disorder: associated problems in attention, learning, and psychosocial adjustment. Hum Mov Sci. 2002;21:905-918

13. Rasmussen P, Gillberg C. Natural outcome of ADHD with developmental coordination disorder at age 22 years: a controlled, longitudinal, community-based study. J Am Acad Child Adolesc Psychiatry. 2000;39: 1424-1431

14. Uauy R, Hoffman DR, Peirano P, Birch DG, Birch EE. Essential fatty acids in visual and brain development. Lipids. 2001;36:885-895

15. Moriguchi T, Greiner RS, Salem N Jr. Behavioral deficits associated with dietary induction of decreased brain docosahexaenoic acid concentration. J Neurochem. 2000;75:2563-2573

16. Bourre JM, Durand G, Pascal G, Youyou A. Brain cell and tissue recovery in rats made deficient in $n-3$ fatty acids by alteration of dietary fat. J Nutr. 1989;119:15-22
17. Wechsler D. Wechsler Intelligence Scale for Children. 3rd ed. London, United Kingdom: The Psychological Corp, Harcourt Brace; 1992

18. Henderson SE, Sugden D. Movement Assessment Battery for Children. New York, NY: The Psychological Corp, Harcourt Brace; 1992

19. Wechsler D. Wechsler Objective Reading Dimensions (WORD). London, United Kingdom: The Psychological Corp, Harcourt Brace; 1993

20. Conners CK. Conners' Parent Rating Scales-Revised. New York, NY: Multi-Health Systems; 1997

21. Schachter HM, Pham B, King J, Langford S, Moher D. How efficacious and safe is short-acting methylphenidate for the treatment of attentiondeficit disorder in children and adolescents? A meta-analysis. CMAJ. 2001;165:1475-1488

22. Hellgren L, Gillberg C, Gillberg IC, Enerskog I. Children with deficits in attention, motor control and perception (DAMP) almost grown up: general health at 16 years. Dev Med Child Neurol. 1993;35:881-892

23. Hellgren L, Gillberg IC, Bagenholm A, Gillberg C. Children with deficits in attention, motor control and perception (DAMP) almost grown up: psychiatric and personality disorders at age 16 years. J Child Psychol Psychiatry. 1994;35:1255-1271

\section{E-MAIL-THE FUTURE?}

"Doctors may no longer make house calls, but they are answering patient e-mail messages, and being paid for it. In a move to improve efficiency and control costs, health plans and medical groups around the country are now beginning to pay doctors to reply by e-mail, just as they pay for office visits. While some computerliterate doctors have been using e-mail to communicate informally with patients for years, most have never been paid for the service. ... Blue Shield of California pays [one patient's] doctor $\$ 25$ for each online exchange, the same as it pays for an office visit. Some insurers pay a bit less for e-mailing, and patients in some health plans are charged a $\$ 5$ or $\$ 10$ co-payment that is billed to their credit card and relayed to the doctor. For doctors, the convenience of online exchanges can be considerable. They say they can offer advice about post-surgical care, diet, changing a medication and other topics that can be handled safely and promptly without an office visit or a frustrating round of telephone tag. And, surveys have shown that e-mail, by reducing the number of daily office visits, gives physicians more time to spend with patients who need to be seen face to face. For patients, e-mail allows them to send their medical questions from home in the evening, without missing work and spending time in a doctor's waiting room. In fact, many say exchanges in the more relaxed, conversational realm of e-mail make them feel closer to their doctors." 


\section{The Oxford-Durham Study: A Randomized, Controlled Trial of Dietary \\ Supplementation With Fatty Acids in Children With Developmental Coordination Disorder}

Alexandra J. Richardson and Paul Montgomery

Pediatrics 2005;115;1360-1366

DOI: $10.1542 /$ peds.2004-2164

This information is current as of May 3, 2005

\begin{tabular}{|c|c|}
\hline $\begin{array}{l}\text { Updated Information } \\
\& \text { Services }\end{array}$ & $\begin{array}{l}\text { including high-resolution figures, can be found at: } \\
\text { http://www.pediatrics.org/cgi/content/full/115/5/1360 }\end{array}$ \\
\hline References & $\begin{array}{l}\text { This article cites } 18 \text { articles, } 2 \text { of which you can access for free } \\
\text { at: } \\
\text { http://www.pediatrics.org/cgi/content/full/115/5/1360\#BIBL }\end{array}$ \\
\hline Subspecialty Collections & $\begin{array}{l}\text { This article, along with others on similar topics, appears in the } \\
\text { following collection(s): } \\
\text { Nutrition \& Metabolism } \\
\text { http://www.pediatrics.org/cgi/collection/nutrition_and_metabolis } \\
\text { m }\end{array}$ \\
\hline Permissions \& Licensing & $\begin{array}{l}\text { Information about reproducing this article in parts (figures, } \\
\text { tables) or in its entirety can be found online at: } \\
\text { http://www.pediatrics.org/misc/Permissions.shtml }\end{array}$ \\
\hline Reprints & $\begin{array}{l}\text { Information about ordering reprints can be found online: } \\
\text { http://www.pediatrics.org/misc/reprints.shtml }\end{array}$ \\
\hline
\end{tabular}

